\title{
Análise de um curso a distância que utilizou uma nova ferramenta de Courseware chamada Moodle
}

\author{
Lisandra Nascimento ${ }^{1}$, Marcelo Leifheit ${ }^{2}$ \\ 1 Pedagoga em Multimeios e Informática Educativa, Pós-Graduanda em Gestão do \\ Capital Humano e consultora pedagógica da empresa Alfamais e-Learning \\ ${ }^{2}$ Administrador de Empresas e sócio-diretor da empresa Alfamais e-Learning \\ \{lisandralves, mleifheit\}@terra.com.br
}

\begin{abstract}
Resumo: Em dezembro de 2004 foi realizado o primeiro curso a distância sobre o tema "Gestão de Projetos", utilizando um sistema de sala virtual síncrona para transmissão das aulas e um LMS baseado em software livre para apoiar as atividades assíncronas. $O$ objetivo do curso era capacitar os participantes a planejar e gerenciar projetos de qualquer natureza, resolver problemas ou oportunidades com rapidez, reunir as pessoas certas para executar o projeto e obter soluções eficazes, dentro de limites de tempo e de orçamento. A necessidade de realizar este curso à distância foi gerada em função da dificuldade da empresa de Consultoria, no atendimento dos seus clientes que estão geograficamente dispersos. A motivação deste trabalho está focada em analisar especificamente a utilização dos recursos tecnológicos das ferramentas de apoio na comunicação a distância disponíveis no Learning Management System (LMS) chamado Moodle e que foram utilizadas na gestão e apoio à interação com os alunos distantes.
\end{abstract}

Palavras chave: e-Learning, Moodle, Conhecimento.

\begin{abstract}
At 2004 December was realized the first course on the theme "Administration of Projects", using a system with a virtual room for synchronous classes transmission and used a LMS based on free software to support the asynchronous activities. The objective of the course was to qualify the participants to drift and to manage projects of any nature, to solve problems or opportunities quickly, to gather the right people to execute the project and to obtain effective solutions, inside of limits of time and of budget. The need to accomplish this course at the distance was generated about the fact of the company difficulty on offer your Consultancy services, for they clients who are geographically dispersed. The motivation of this work is focused in analyzing the use of the technological resources specifically on the support of the distance communication tools, available in Learning Management System (LMS) called Moodle and that they were used in the administration and support to the interaction with the distant students.
\end{abstract}

Key words: e-Learning, Moodle, Knowledge.

\section{Introdução}

A utilização do e-learning pode oferecer diversas vantagens para as empresas, tais como, a redução nos custos de viagem, ausência dos colaboradores nos postos de trabalho, maior interatividade entre pessoas distantes, formação de comunidades multidisciplinares virtuais, redução de custos, disponibilização de informações atualizadas e segmentadas, desenvolvimento de cursos personalizados, gestão do conhecimento, gestão e armazenamento de informações, entre outras. 
Conforme Rosemberg (2002), um dos importantes benefícios propiciados por um sistema de e-learning é a possibilidade que se abre para a Gestão do Conhecimento. A utilização de sistemas informatizados de armazenamento e controle de acesso às informações, pode, a custos reduzidos, facilitar a disseminação do conhecimento dentro e fora das organizações, o que é algo fundamental atualmente em virtude da rapidez com que as mudanças acontecem no mercado. A possibilidade de distribuição e troca de informações, que facilitam o compartilhamento de experiências entre pessoas distantes, são alguns dos pontos chave para o desenvolvimento e crescimento de comunidades virtuais de aprendizagem.

O presente estudo foi desenvolvido especificamente em três momentos distintos. Num primeiro momento apresentamos a contextualização teórica da sociedade em rede e os motivos pelos quais a empresa de Consultoria M\&M buscou na metodologia de elearning, uma solução prática para o problema de atendimento dos seus clientes distantes.

Num segundo momento, serão apresentadas as características da ferramenta de e-learning selecionada e os motivos da escolha. Nesta etapa, serão apresentados os recursos de interação on-line e os recursos de gestão e controle dos acessos dos alunos participantes.

No terceiro e último momento, encerramos este estudo com as conclusões obtidas ao final do curso "Gestão de Projetos".

\section{Justificativa para o uso do e-Learning}

Mediante as inúmeras inovações o conhecimento tornou-se o grande diferencial competitivo para as empresas e organizações que querem estar conectadas com as mudanças. Mas por outro lado, junto às inovações vem a grande quantidade de informações que as pessoas precisam ter acesso diariamente para estarem por dentro do mundo dos negócios. Conforme Leifheit (2001), a velocidade das mudanças no mercado globalizado e a facilidade com as informações circulam pela rede mundial de computadores, exige que os profissionais que queiram permanecer no mercado de trabalho mantenham a sua atualização profissional constante, pois para manter o foco do negócio da empresa é preciso rapidez, flexibilidade de adaptação pessoal e conhecimentos atualizados. Projetar as experiências do passado para o futuro resulta em uma prática cada vez menos eficaz. A nova conjuntura é caracterizada por mudanças muito rápidas e pouco relacionada com situações anteriores.

As redes são, segundo Castells (2000), processos que necessitam de comunicação que ultrapassam qualquer limite de distância, são estruturas abertas, dinâmicas, que aceitam qualquer tipo de mudança. As redes apenas necessitam que os indivíduos falem os mesmos códigos, ou seja, consigam se comunicar. Através das redes os indivíduos formam comunidades que necessitam de comunicação, que compartilham interesses comuns que formam uma comunicação global com um grande diferencial de não dependerem do lugar para que esses possam compartilhar seus interesses. Assim, a informação e o conhecimento adquirem cada vez mais importância no mundo dos negócios. Conforme Pallof e Pratt (2002), transformar a informação em conhecimento parece ser a chave para enfrentar os desafios de estar sempre se desenvolvendo, aprendendo e integrando diariamente os processos de mudança. As organizações estão transformando-se sob esta realidade e mudando suas posições conservadoras para adotar novas estratégias que assegurem a sua sobrevivência no mercado. 
À medida que as inovações começam a se mostrar presentes nas organizações, estas começam a sentir dificuldades para se adaptar às novas exigências, pois as organizações na sua maioria estão estruturadas de forma burocrática e não conseguem absorver de forma natural as modificações como precisariam. A metáfora da máquina versus seres vivos que Castells (2000), relata, nos mostra de forma clara essa problemática que as organizações vivem no dia a dia. Os administradores, em geral, contemplam as organizações como se essas fossem máquinas que precisam de comandos e de manutenção a todo o momento, mas na verdade, as organizações deveriam ser contempladas como um sistema vivo que trabalha com pessoas e estas possuem características próprias como flexibilidade, potencial criativo e capacidade de aprendizado.

Algumas empresas consideram que uma estratégia inovadora é o investimento no desenvolvimento das habilidades e competências de seus funcionários, o que fará com que possam alcançar os objetivos pretendidos. Desta forma, investir na gestão do conhecimento torna-se um grande diferencial competitivo. Assegurar o conhecimento dentro das organizações significa chegar ao aprendizado, disseminar as idéias e inovações de forma veloz, melhorando os fluxos de informação e transformando as oportunidades destacadas da visão estratégica da empresa. "Trabalhar para uma organização voltada para a criação de conhecimentos é uma motivação maravilhosa não porque a organização terá mais lucro, mas porque nossa vida valerá mais a pena" (LÉVY, 1999, p. 56). A valorização do conhecimento, esta característica que antes parecia pertencer às instituições de ensino, atualmente é parte de todo tipo de organização, que procura métodos viáveis, flexíveis, rápidos, atualizados, alinhados com seus objetivos para desenvolver programas de capacitação e desenvolvimento, sem barreiras de tempo, lugar e de número de pessoas.

Uma das soluções propostas para essa finalidade é o e-learning. O e-learning possibilita o desenvolvimento de programas de capacitação e a gestão do conhecimento produzido dentro de organizações que querem compartilhar e disseminar de maneira rápida e eficaz as informações. A capacitação e gestão do conhecimento dentro das organizações podem se dar por meio da formação de comunidades virtuais de aprendizagem com o uso de sistemas de aprendizagem a distância.

A Empresa M\&M Consultoria de Projetos, possui sua sede própria localizada em Porto Alegre, mas atua em projetos de clientes em vários estados brasileiros. Com uma equipe de consultores altamente especializada para atender as demandas de seus clientes, conta com um pessoal efetivo reduzido, permitindo-lhe competitividade nos custos que são repassados aos seus clientes. Em contrapartida, seus novos e importantes clientes começam a exigir que a Empresa M\&M realize cobertura nacional de atendimento para as filiais e representantes de vendas.

A Empresa M\&M, no entanto, não possui demanda suficiente de atividades regulares e trabalhos que justifiquem o investimento em novas contratações fora do estado do Rio Grande do Sul. Os deslocamentos regulares de seus consultores locais, no entanto, são necessários para manter o vínculo e os contratos de prestação de serviços com seus clientes e parceiros que estão dispersos geograficamente. Porém, o alto custo associado ao transporte, diárias, tempo de espera e ausência no local de trabalho, estão começando a reduzir as margens de lucros da Empresa M\&M.

Para minimizar os custos com deslocamentos, manter a regularidade dos seus treinamentos e possibilitar a troca de informações padronizadas e personalizadas com seus clientes, a Empresa M\&M Consultoria optou pela utilização de uma ferramenta de apoio a comunicação à distância, chamada LMS (Learning Management System). Além de possibilitar uma considerável melhora no atendimento dos seus clientes através dos recursos de interação para administração de cursos e comunicação eletrônica pretende 
reduzir custos e potencializar investimentos em novas contratações de consultores efetivos.

A utilização da ferramenta LMS se justifica como sistema de apoio ao treinamento promovido pela empresa M\&M Consultoria de Projetos e que necessita suprir demandas pontuais de capacitação atendendo com informações personalizadas os seus clientes que estão espalhados em diversas cidades do Brasil. O curso "Gestão de Projetos" foi selecionado pela empresa M\&M Consultoria de Projetos para referenciar a comparação das metodologias presencial versus e-learning no intuito de verificar a viabilidade comercial de uso desta metodologia como possibilidade de negócio futuro para sua empresa.

\section{Objetivos deste trabalho}

Conforme o contexto apresentado, o objetivo específico deste estudo consiste em:

$\rightarrow$ Caracterizar a utilização dos recursos de interação on-line de um LMS (Learning Management System), com base em um estudo de caso corporativo de um curso a distância.

$\rightarrow$ Analisar os resultados de aprendizado dos alunos do curso, em comparação ao ensino presencial, a partir dos relatórios do sistema, registros de diários, interações no fórum de discussão, observações e entrevista com o professor.

$\rightarrow$ Refletir sobre o uso de uma ferramenta de Sala Virtual síncrona para a transmissão das aulas do curso.

\section{Desenvolvimento do Estudo de Caso}

A ferramenta LMS Moodle, foi selecionada para ser utilizada como apoio para implantação do projeto junto à empresa M\&M, dentre inúmeras opções de LMS disponíveis no mercado, pelos seguintes motivos:

$\rightarrow$ Custos baixos de implantação e disponibilização do sistema para a empresa M\&M, por ser um sistema desenvolvido em plataforma livre (PHP), ou seja, por rodar sobre uma distribuição gratuita de GNU/LINUX.

$\rightarrow$ Não possuir custos de aquisição e royalties de uso.

$\rightarrow$ Facilitar a operação por usuários leigos em programação visual, permitindo que a maior parte das áreas de texto (fontes, recursos, fóruns, notícias) possam ser editados, usando um editor HTML WYSIWYG incorporado, e que os conteúdos possam ser facilmente adaptados e disponibilizados para os alunos.

$\rightarrow$ Possuir tradução integral das interfaces para a língua portuguesa.

$\rightarrow$ Possuir suporte gratuito pela comunidade internacional de usuários e atualização gratuita de recursos via Internet.

\subsection{Características da ferramenta de apoio LMS Moodle}

O LMS Moodle é um software baseado em ambiente de Internet desenvolvido para produzir, hospedar e gerir cursos baseados em Internet e formação de comunidades 
virtuais. Trata-se de uma plataforma que pertence a um projeto de contínuo desenvolvimento e que serve para apoiar projetos de educação a distância baseados na filosofia construtivista. Moodle é um sistema distribuído livremente como software de código fonte aberta (que roda sobre uma Licença Pública de GNU/Linux) e que após devidamente instalado em servidor conectado à Internet, pode ser acessado por qualquer Browser que entenda a linguagem PHP e pode suportar vários tipos de banco de dados (particularmente o MySQL). Moodle é um sistema registrado, mas que permite liberdades adicionais típicas de um sistema desenvolvido em free software, tais como: copiar, usar e modificar seus códigos, contanto que a fonte do sistema e seu autor sejam sempre disponíveis aos usuários interessados. Esta plataforma de Educação a Distância opera em mais de 980 sites distribuídos em 74 países, sendo que é totalmente compatível com navegadores de Internet (browsers) como Internet Explorer, Mozilla e Netscape. O suporte do sistema é feito por uma comunidade internacional com excelente tempo de resposta, o que garante o funcionamento e a customização desta ferramenta para diversas necessidades e aplicações.

\subsection{Funcionalidades do sistema LMS}

O Sistema Moodle foi desenvolvido com base numa pedagogia social construtivista que envolve possibilidade de troca de informações e de colaboração em atividades cujas reflexões e críticas podem ser compartilhadas entre todos os usuários do sistema ou mais propriamente, da comunidade virtual a qual o aluno usuário está matriculado. O sistema é adequado para atividades $100 \%$ a distância (on-line) ou ainda pode apoiar e complementar atividades do ensino presencial (atividades híbridas, blended learning).

Possui uma interface simples, intuitiva, leve, eficiente, compatível; interface para browsers de baixa complexidade.

Gerenciamento do site: $\mathrm{O}$ site é gerenciado pelo administrador usuário, definido na instalação.

Gerenciamento de usuários: Cada usuário requer apenas uma conta para todo servidor, sendo que cada conta possui diferentes acessos/permissões, ou seja, perfis de acesso diferenciados. A conta de administrador controla a criação de cursos e cria permissões para professores indicando usuários para isso, sendo que uma conta de criador de cursos permite apenas a criação e tutoria dos cursos.

Gerenciamento dos cursos: O professor de um curso possui controle sobre toda a configuração do curso, permitindo inclusive a escolha do formato do curso como: curso semanal; curso focado em tópicos; curso em formato social. As atividades do curso flexíveis tais como Fóruns, Notícias, Quizzes, Recursos, Escolhas, Exercícios, Avaliações, Chats, Workshops também são programadas pelo professor. A maior parte das áreas de texto (fontes, recursos, fóruns, notícias) podem ser editados usando um editor HTML WYSIWYG incorporado. Todas notas para os Fóruns, Notícias, Quizzes e Avaliações podem ser visualizadas em uma página (e armazenadas em um arquivo para download) e ainda o rastreamento total das atividades do usuário - relatórios de atividades para cada estudante estão disponíveis com gráficos e detalhes sobre cada módulo (últimos acessos, tempo em cada acesso) assim como um histórico detalhado para cada estudante envolvendo postagens, envio de notícias, e outros em uma página. A integração de correio do correio eletrônico permite que as cópias dos tópicos dos fóruns, feedback do professor, possam ser enviados por e-mail em formato HTML ou texto plano. A escala de avaliação pode ser customizada pelos próprios professores, o que lhes permite definir suas próprias escalas para serem usadas para avaliar fóruns, avaliações e notícias. 
Módulos de interação entre os usuários: serão descritos a seguir, os módulos que permitem a troca de informações entre os usuários do LMS Moodle. O Sucesso na comunicação interativa ocorre especificamente através do conhecimento por parte dos usuários da manipulação adequada dos recursos disponíveis.

Módulo de Tarefas: Este módulo auxilia o facilitador a conduzir tarefas e avaliar os alunos. O feedback do professor é adicionado na página da tarefa para cada aluno, e uma notificação é enviada por e-mail.

Módulo de chat: Este é o único módulo do sistema que permite interação síncrona por texto entre os alunos e o facilitador. Permite aos participantes visualizar as fotos dos seus colegas na janela de chat.

Módulo de Enquete: De modo similar a uma pesquisa, pode ser usado para votação ou para obter feedback de cada estudante.

Módulo de Fórum: Os diferentes tipos de fóruns são disponibilizados exclusivamente pelos professores e são utilizados para a comunicação assíncrona entre os participantes ou ainda para a publicação de notícias dos cursos. Podem ser criados quantos fóruns de discussão forem necessários.

Módulo Quizz: Com base nos princípios da "Taxonomia de Bloom" (referência?) o sistema Moodle permite a publicação e correções automáticas de questões em diversos formatos tais como: de respostas curtas (palavras ou frases), de verdadeiro ou falso, de relacionamento, randômicas, numéricas, textos descritivos e com imagens integradas.

Módulo de Arquivo: Serve para carregar arquivos para o servidor de um modo prático e simples. Suporta exibição de qualquer conteúdo eletrônico, Word, PowerPint, Flash, vídeo, sons, entre outros.

Módulo Workshop: Permite compartilhamento e trabalho conjunto dos alunos em documentos e o professor pode gerenciar e avaliar o trabalho. Os professores podem prover exemplos de documentos para exercícios práticos.

Módulo Glossário: Este módulo permite a criação de um dicionário com definições dos termos usados nos conteúdos dos cursos.

\subsection{Desenvolvimento do curso}

Visando atender a necessidade de capacitação de clientes da empresa M\&M Consultoria de Projetos, sobre o assunto "Gestão de Projetos" e considerando que estes clientes estão dispersos geograficamente, optou-se pelo desenvolvimento de um curso na modalidade de e-Learning. Para gerenciar os acessos e organizar a comunicação entre os participantes foi utilizado o sistema gerenciador de aprendizado (LMS) Moodle.

O desenvolvimento do curso contou com o apoio da empresa Alfa+ e-Learning, que possui na sua equipe consultores com mais de seis anos de experiência em projetos de e-Learning.

Antes da integração dos conteúdos na plataforma de e-learning, o início do projeto de capacitação foi composto por diversas reuniões entre os profissionais da empresa M\&M e Alfa+, que repassaram as metodologias e melhores práticas para o adequado desenvolvimento de comunicação via Internet. A integração dos conteúdos na plataforma, bem como a estrutura das aulas, sistemas de avaliação e atividades de trabalho do curso, foram planejados previamente nestas reuniões no intuito de integrar o curso adequadamente no LMS de acordo com as expectativas de resultados esperados pelos consultores da M\&M.

O curso foi desenvolvido em dezembro de 2004, como resultado pode-se observar o aspecto colaborativo das equipes multidisciplinares que integraram as perspectivas teóricas do conteúdo do curso com experiências práticas de aprendizagem

\footnotetext{
$6-$ V. $3 \mathrm{~N}^{\circ}$ 1, Maio, 2005
} 
on-line. As características de interação do LMS Moodle foram combinadas ao desenvolvimento do conteúdo de acordo com uma estrutura diária de condução dos conteúdos, em que os alunos eram conduzidos a desenvolver as dinâmicas de leitura e tarefas de acordo com um cronograma de aulas e atividades que foi previamente disponibilizado no manual do aluno. O plano de curso foi desenvolvido durante três semanas e estava baseado em uma estrutura de conteúdos interdependentes. No primeiro encontro síncrono foi realizada uma introdução em que os objetivos de curso foram apresentados e discutidos, todos os participantes tiveram a oportunidade de se apresentar através da Sala Virtual e de um fórum de discussão chamado "Conheça seus Colegas". Todos os estudantes preencheram um formulário on-line no qual puderam escolher a consentir ou não com as informações que seriam compartilhadas entre o grupo, todos aceitaram e mostraram-se contentes com a possibilidade de interação. Durante o curso, os alunos foram convidados a escrever informações nos fóruns on-line de acompanhamento no qual foram exigidos que refletissem a respeito do conhecimento atual a respeito dos assuntos do curso. As atividades síncronas foram desenvolvidas durante sete encontros através da Sala Virtual com a duração média de duas horas por encontro. As aulas foram dispostas em um padrão cognitivo de construção de conhecimentos, em que os assuntos foram sendo montados como em um projeto. Para cada estudante foi solicitado que durante o período do curso fossem desenvolvidas as seguintes atividades individuais: (i) leitura de artigos relacionados com os assuntos do curso; (ii) desenvolvimento de um dos tópicos dos fóruns de discussão, procurando solucionar as dúvidas de seus colegas; e (iii) elaboração de registros em três diários correspondentes a antes da leitura, depois da leitura, e depois da discussão. Os diários foram avaliados cada semana pelo tutor que proveu avaliação individual e conceitual conforme as interações dos alunos através dos fóruns de discussão, e-mail, tarefas programadas e nas aulas síncronas.

As interações com os alunos e professores foram conduzidas livremente através da Sala Virtual, dos fóruns de discussão e e-mail, sendo que cada colaborador pôde trazer ao conhecimento de todos os assuntos específicos, desde que estivessem relacionados com os conteúdos abordados no curso. Visto que a turma era composta de pessoas adultas, foram utilizados conceitos andragógicos de desenvolvimento, através das implicações dos conteúdos do curso que eram direcionadas principalmente para a reflexão das atividades profissionais dos alunos com as práticas de aprendizagem pessoais.

As pesquisas de reação on-line, auxiliaram o facilitador/orientador a obter indicações de qualquer mudança de satisfação que poderia estar acontecendo em aspectos fundamentais do ambiente de aprendizagem on-line durante o curso, em que quaisquer mudança poderia ser rapidamente identificada e tratada .

\section{Conclusões}

Ao término do curso, nosso julgamento era que o curso parecia ter tido bastante êxito alcançando as metas de aprendizagem originalmente propostas. Esta avaliação estava baseada nas experiências prévias com o sistema de sala de aula tradicional em comparação com a metodologia de ensino e de aprendizagem realizada no curso a distância e que foi analisada através do monitoramento das interações dos estudantes em declarações feitas em entradas de diário, interações pelos fóruns de discussão, composições de tarefas individuais, através da Sala Virtual e da análise informal de avaliação através da opinião do professor.

As pesquisas de satisfação mostraram que os estudantes estavam exibindo empatia com os colegas e indicou que todos os participantes experimentaram um 
agradável e estimulante ambiente de aprendizagem. Os estudantes determinaram nas suas avaliações individuais que o curso e a metodologia utilizada para a condução dos conteúdos foi bastante satisfatória, porém, em virtude da profundidade dos conteúdos abordados, foi sugerido que o curso deveria ter sua carga horária estendida. No entanto, apesar das baixas contagens indicativas de problemas de interatividade e apoio pedagógico por parte do facilitador, uma questão foi levantada: Dado que os estudantes obtiveram uma alta indicação de interações on-line, por que cinco dos seis estudantes indicaram que iriam preferir uma maior quantidade de interações e apoio individualizado do facilitador? Para responder esta pergunta foi observada a qualidade de interações por diálogo no próprio ambiente de aprendizagem e nos e-mails trocados entre os alunos e o professor. A pesquisa realizada incluiu declarações pessoais, com as quais muitos alunos constantemente concordavam com as opiniões dos colegas. Porém, um exame detalhado dos textos não revelou evidências de que os alunos dirigiam perguntas a outros estudantes com o intuito de construir seus pensamentos nas idéias deles/delas ou ainda se basear nas motivações deles/delas. Ao invés disto, os estudantes tenderam a apoiar suas declarações com base nos seus próprios pensamentos e experiências pessoais. Essa observação pode ser interpretada como uma limitação de interação do ambiente virtual, que em determinadas situações pode limitar a construção de uma aprendizagem colaborativa baseada em experiências profissionais com pessoas estranhas entre si e pertencentes a setores e ramos distintos das áreas de comércio, serviços e indústria.

De um modo geral, conclui-se que os objetivos contratados junto aos alunos foram plenamente atingidos, uma vez que os mesmos tiveram expressiva participação nas interações com o facilitador. Segundo a opinião do professor responsável por conduzir as aulas on-line, a diferença fundamental de um programa de treinamento tradicional e o e-Learning é que a falta de presença física dificulta o entendimento das dúvidas dos alunos, que muitas vezes não conseguem expressá-las adequadamente por escrito. Porém, no âmbito geral, o resultado de aprendizado possui maior interação, pois ao considerar as possibilidades de troca de informações entre os alunos e entre o facilitador, concluiu-se que o e-Learning contribui para que os participantes aprendam de um modo mais eficaz, pois há o estímulo à participação ativa no processo de construção do aprendizado. No formato tradicional os alunos são, muitas vezes, agentes passivos do processo de ensino e de aprendizagem, absorvendo as informações que lhes são repassadas e que somente no futuro irão buscar relação com a prática efetiva. Já os alunos usuários da metodologia e-learning são conduzidos pelo professor a gerenciar seu aprendizado como mais uma atividade importante do seu dia, onde são estabelecidas metas, objetivos, prazos e planos estruturados de estudo. No entanto, somente os alunos que possuírem senso de propriedade, autonomia e responsabilidade adequada, serão aptos a serem alunos on-line.

\section{Referências}

CASTELLS, Manuel. A Sociedade em Rede. 3.ed. São Paulo: Paz e Terra, 2000.

LÉVY, Pierre. O que é virtual. São Paulo: 34. 1999

ROSEMBERG, Marc J. E-learning. São Paulo: Makron, 2002

LEIFHEIT, Marcelo. The Continuous Education Solution for a Country Wide Telecommunication Company, ED-Media 2001 Tampere, Finland.

PALLOF Renan; PRATT Keith. Construindo Comunidades de Aprendizagem no Ciberespaço. Estratégias Efetivas para Cursos Online. Porto Alegre: Artmed.2002. 
